\title{
The Story of a Dream: From Vienna to Tehran
}

\author{
Reza Fekrazad, ${ }^{1,2, *}$ and Katayoun AM Kalhori ${ }^{3}$ \\ ${ }^{1}$ Department of Periodontology, Dental Faculty - Laser Research Center in Medical Sciences, AJA University of Medical Sciences, Tehran, Iran \\ ${ }^{2}$ International Network for Photo Medicine and Photo Dynamic Therapy (INPMPDT), Universal Scientific Education and Research Network (USERN), Tehran, Iran \\ ${ }^{3}$ Iranian Medical Laser Association, Tehran, Iran \\ "Corresponding author: Reza Fekrazad, Department of Periodontology, Dental Faculty - Laser Research Center in Medical Sciences, AJA University of Medical Sciences, Tehran, \\ Iran. E-mail: rezafekrazad@gmail.com
}

Received 2017 March 05; Accepted 2017 March 06.

Since one hundred years ago when Albert Einstein Propounded the theory of stimulated emission of radiation (1), scientists tried to develop this theory and in 1959 Gordon Gould published the term LASER in the paper "The LASER, light amplification by stimulated emission of radiation (2)". Finally in 1960, the famous article of Maiman was published in the Nature Journal, by this way the first LASER system entered the science in the format of Ruby LASER(3). At the same time scientists were on the opinion that LASER is an answer to many not-propounded questions, therefore, since the same years they have asserted that LASER is an answer to these questions.

The first precious fields that LASER could find a place for itself in were ophthalmology and surgery. A few years later with the development of LASER Technology and the improvement of its ability, a good situation was provided for this technology to be used for hard tissues in the dentistry Science.

LASER in the recent years has proved that it can be of use in diagnosis, surgery, and therapeutic fields in the dentistry Science. Like many other modern sciences, many reputable organizations have been established for the development and improvement of this modern technology.

One of the main goals of these associations is organizing international congresses in which the scientists from all over the world help to develop this modern science by sharing their ideas.

One of these organizations is European Society for Oral Laser Application in Dentistry (ESOLA) which held its first international congress on 2001 in Vienna (Figure 1).

Concerning this issue, for the first time a two-person Team from Iran only with a paper in the poster format could attend this Congress (of course the research activities in this field had been started a few years before this congress in Iran, but this was the first international presence of Iran in this type of international congresses).

The big dream of this team was that if it would be possible to organize this congress in Iran at a proper time in near future and if Iran would be signified as a powerful resource of this science in the world.

ESOLA continued its scientific activities and after a few

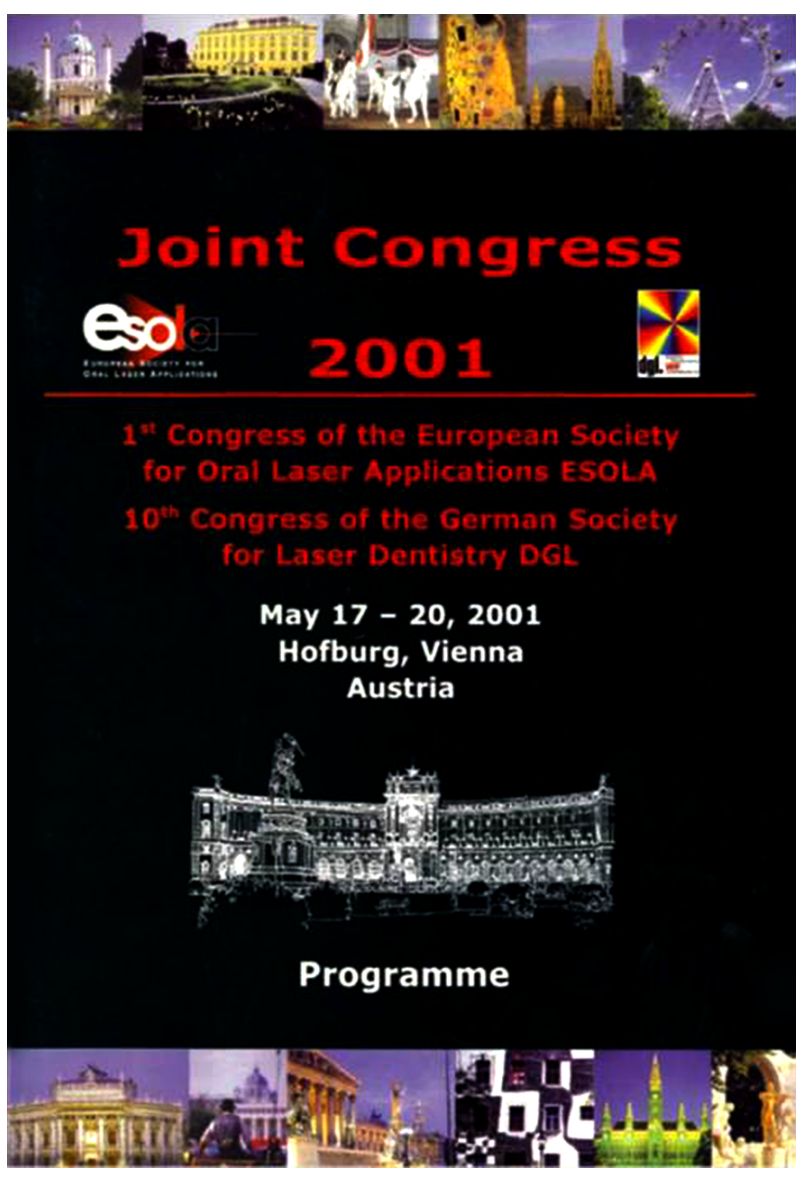

Figure 1. First International Congress

years changed its title to SOLA (international society for oral laser application). This society, at present, is 16 years old and has held many congresses in Spain, Belgium, Italy, China, India, and other countries.

The Iranian team started its efforts to develop this technology and by creating research centers tried to reach its dreams. This team, also, started its effort for introducing this technology to the Medical Society and in spite of many difficulties, problems, and sever resistance could develop

Copyright (c) 2017, AJA University of Medical Sciences. This is an open-access article distributed under the terms of the Creative Commons Attribution-NonCommercial 4.0 International License (http://creativecommons.org/licenses/by-nc/4.0/) which permits copy and redistribute the material just in noncommercial usages, provided the original work is properly cited. 
and prove their viewpoints regarding useful LASER applications. They participated in the international congresses and joined international organizations like world federation for laser dentistry (WFLD) and world association for laser therapy (WALT) and by offering the best lectures could obtain the highest rates (like Barcelona and Dubai congress) (Figures 2 and 3 ) and even in WFLD congress in Japan could stand on second place of presentation counts (Figures 4 and 5).

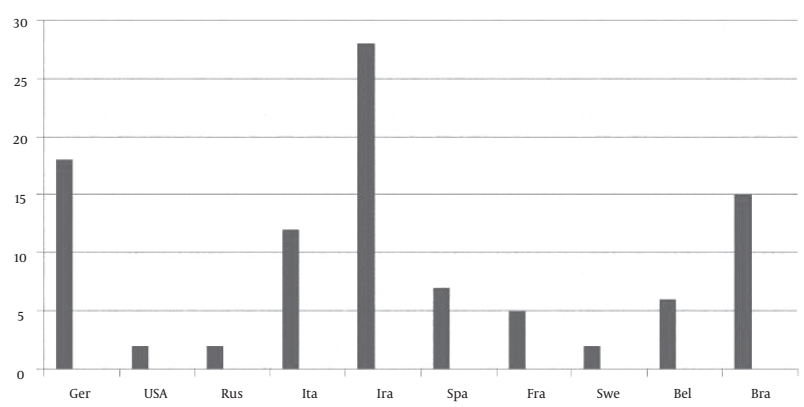

Figure 2. Distribution of Presentations According to the Countries Attending in WFLD Congress, Dubai 2010

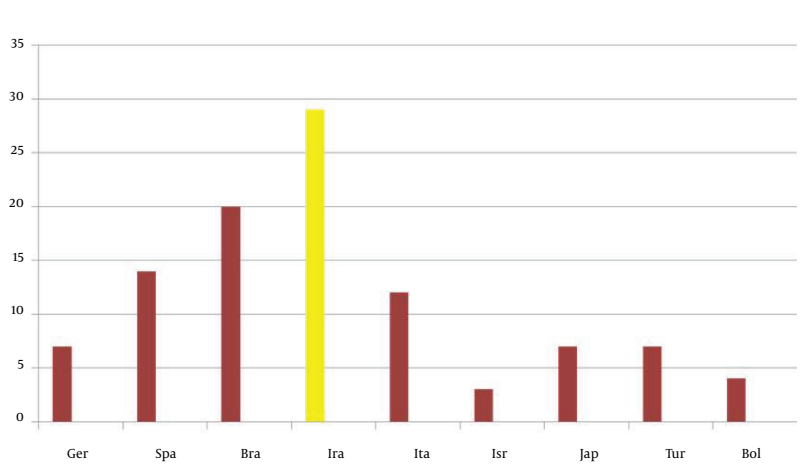

Figure 3. Distribution of Oral Presentations According to the Countries Attending in WFLD Congress, Barcelona 2012

In addition, they decided to expand their scope of activities to the academic fields, and a national plan under the title of Plan of development and advancement of laser dentistry (PDALD) (4) on state and ministry levels had been designed and accordingly a LASER training course for use in dentistry curriculum was provided and published.

According to our information, Iran is not only the first country in the region, but perhaps in the world that could hold such courses in the majority of the country's universities.

In addition to the cooperation of Tehran university and Aachen university, they designed and executed a course for

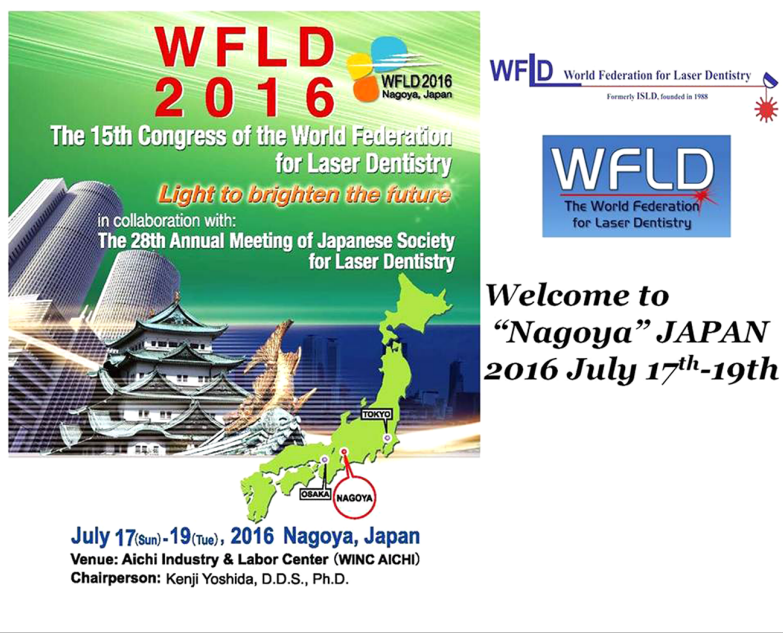

Figure 4. The 15th Congress

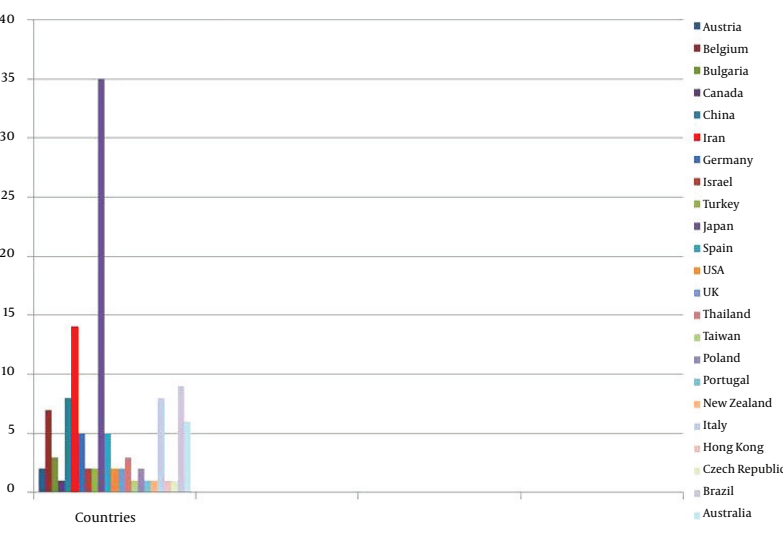

Figure 5. Distribution of Oral Presentation According to the Countries Attending in WFLD Congress, Nagoya - Japan, 2016

training instructors for expanding the level of this technology all over Iran (5), and gradually by cooperating with other countries such as America, South Africa, Germany, England, Sweden, Norway, and some others, not only was a suitable situation provided for joint research activities, but also the scientific credibility of participating countries was improved.

After constructing these infrastructures, Iran gradually was accepted as a scientific center in the region and a high stance was provided for our country in the international level in a way that the first congress of Asia-Pacific division of WFLD with close cooperation with FDI and Iranian dental association (IDA) and the presence of 10 international lecturers was held in Iran and according to the participants and the head of this branch, it was one of the most successful congresses of this federation (6)(Figure 6). 


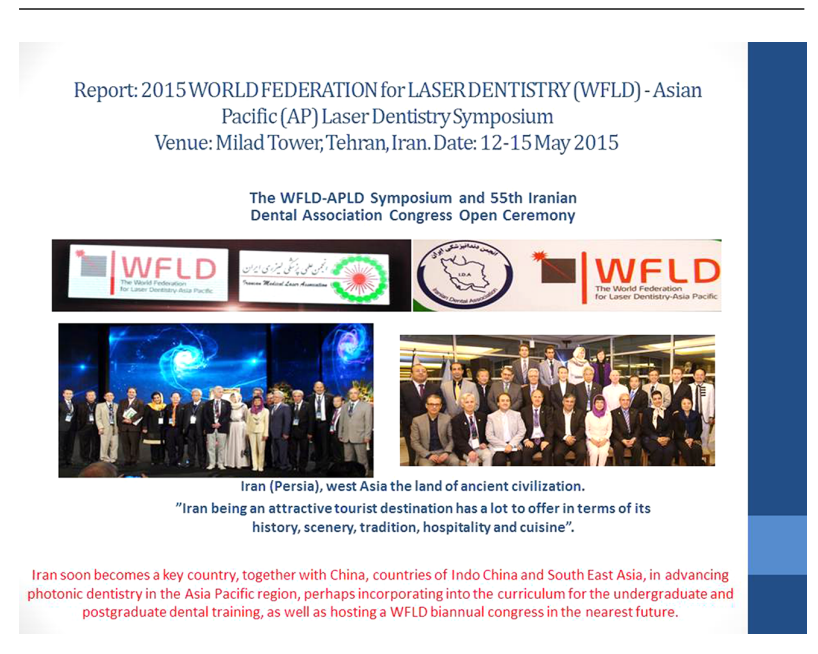

Figure 6. The First Congress of Asia-Pacific Division of WFLD

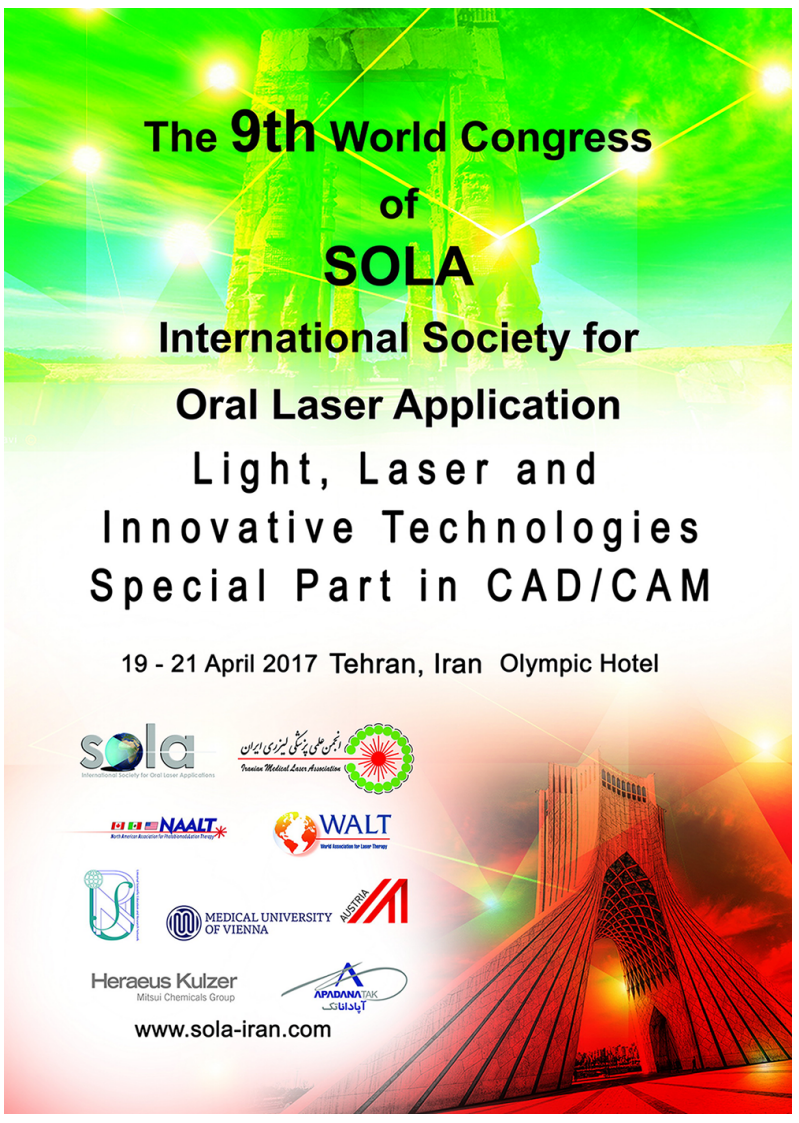

Figure 7. The 9th World Congress of SOLA

Anyhow, gradually this dream "from Vienna to Tehran" comes true and Iran is going to host the $9^{\text {th }}$ world congress of SOLA on April 2017 (7) (Figure 7).
To sum up, we can say that this little team with the cooperation of other researchers has made a famous Iranian Proverb come into reality: "where there is a will, there is a way".

"All we do today has been nothing except a dream for some people in the past. And now we believe that we can reach our present dreams in the near future."

Welcoming message of the Congress

Dear Colleagues,

We are honored to invite you to attend The $9^{\text {th }}$ world congress of international society for oral laser application (SOLA), with the motto of "light, laser, and innovative technologies and special part" which will be held in Tehran on April $19^{\text {th }}-21^{\text {th }} 2017$.

With the support of international society for oral laser applications (SOLA), in co-operation with the world association for laser therapy (WALT), north American association for laser therapy (NAALT), universal scientific education and research network (USERN), and Iranian Medical laser association (IMLA), it is a new opportunity to promote oral laser to improve the standard of oral laser clinical application and research to carry out oral laser standardized training and to expand the international communication.

International society for oral laser applications (SOLA) is a worldwide authoritative oral laser academic organization. International congress of SOLA is famous for high academic standards. It has been held in Austria, Italy, Spain, Belgium, India, China, etc. over the past 10 years and those congresses were great events for oral laser clinicians and scientific researchers, thus, further promoted the development of local academic level for oral laser applications.

Although, laser is a new technology to promote oral medicine after the dental implant, at present Iran is one of the developed countries in using laser in medicine. Iranian specialists have succeeded in indigenizing sections of laser sciences, and have used it greatly in their oral clinical work. It has been widely used along with the development of oral laser devices and updating technology. Major objectives of the Iranian Medical laser association appropriate education and culture in making optimum use of the laser.

In this congress, Medical council of Iran and 7 Medical Sciences Universities and 10 specialized dentistry Societies and 6 LASER Research centers will have a potential presence.

More than 25 well-known international oral laser experts from 12 countries and national speakers will make speech. Also, SOLA standardized training course will be provided before the congress.

We look forward to welcoming you to Iran-Persia the land of ancient civilization, history, culture, and art in April 2017. 
Faithfully Yours,

Reza Fekrazad

Secretary general of world association for laser therapy

(WALT)

President of Iranian Medical laser association (IMLA)

Chairman of Congress

\section{References}

1. Einstein A. Zur Quantentheorie der Strahlung. Physikalische Zeitschrift. 18: 121-128: Bibcode:1917PhyZ...18..121E; 1917.
2. Gould RG, editor. The LASER, light amplification by stimulated emission of radiation. The Ann Arbor Conference on Optical Pumping, the University of Michigan. 15 June through 18 June 1959; p. 128.

3. Maiman TH. Stimulated optical radiation in ruby. Nature. 1960;187(4736):493-4. doi: 10.1038/187493a0.

4. Fekrazad R, AM Kalhori K. The plan of development and advancement of laser in dentistry (PDALD). International magazine of laser dentistry. 2009;3:40.

5. Fekrazad R, AM Kalhori K. The Joint fellowship course of Tehran and Aachen Universities - An academic and scientific joint program. International magazine of laser dentistry. 24 Jun 2011;44.

6. Tehran 2015 - Asia Pacific Laser Symposium Available from: http:// wfldlaser.com/tehran-2015-asia-pacific-laser-symposium/.

7. 9th world congress of SOLA Available from: http://sola-iran.com/en/ page.php?rid=41. 